\title{
Influence of Porous Structure on the Machining Performance of Micro EDM
}

\author{
Rimao Zou, Zuyuan Yu*, Wei Li, Meigang Guo, Jianzhong Li
}

Key Laboratory for Precision and Non-traditional Machining Technology of Ministry of Education, School of Mechanical Engineering, Dalian University of Technology, Dalian, P. R. China

Email: *zyu@dlut.edu.cn

\section{Abstract}

Porous metals are widely used in acoustic or heat absorbing material, heat exchanger, catalysis and biochemical products. Porous metals are available to be processed by electrical discharge machining (EDM). However, the relationship between machining parameters and performance is unclear. In this investigation, extensive experiments are conducted on solid stainless steel 304 and porous stainless steel 304 with different pore sizes. Material removal rate $(M R R)$ and tool wear ratio $(T W R)$ are used to evaluate the machining performance of micro EDM. It was found that the machining of porous metal has a higher $M R R$ and lower TWR than those of solid one. It was also found that the machining performance is significantly affected when the size of porous metal is close to the discharge gap. The abilities of debris removal and machining in porous metal machining by EDM are proposed to analyze this phenomenon. Experimental results match the calculated values well. It is helpful to select proper machining parameters of micro EDM to process porous metals.

Keywords: Micro EDM; porous metal; machining performance; micro structure. 


\section{Introduction}

Porous metals have low density, large specific surface area and excellent energy absorption characteristics besides the electrical conductivity, weldability and ductility of metallic materials (Liu, 2004). An ideal application of porous metal would be a part which served as a light-weight panel, carried acoustic or heat absorbing functions and absorbed energy in crash situations in automotive and railway industry (Banhart, 2001). The property of high specific surface area provides a high interface area between the catalyst and the gases or liquids to be reacted affected, making porous materials prime candidates for catalysis (Banhart, 2001; Mohazzabi and Hill, 2013). Porous metals with a high conductivity can be used as heat exchangers (Banhart, 2001). Some kinds of porous metal could serve as supports for the active material in lead acid batteries, which allows for constructing very light electrodes (Banhart, 2001). In order to increase the overall efficiency, porous metal was used between the combustor and the turbine section of a turbojet engine (Azzi et al., 2007). Porous metals are also very commonly used as biomaterials (Dewidar et al., 2007; Liu, 2004). They have become a kind of biomaterials that may enhance bone fixation and are wildly used in hip and knee replacement surgery (Muth et al., 2013). A variety of 3D porous surfaces or structures have been used to enhance biological fixation on orthopedic implants (Muth et al., 2013). In order to embed sensors and other micro devices to monitor the conditions of artificial bone, micro features such as micro cavities or micro holes needed to be generated. High surface quality and accuracy of micro features in these bones are desired. It is necessary to find a suitable method to generate micro features in these bones.

Micro EDM has the ability of processing any electrically conductive material regardless of its hardness and strength. Micro features such as 3D cavities and micro holes with high aspect ratio are generated in metals with high accuracy, fine surface quality and no burrs (Chung et al., 2011; Rajurkar et al., 2006). Hence, micro EDM is suitable to machine microstructures in porous metals.

In EDM, material is removed by thermal energy generated by electrical discharges. The thermal properties of porous metals may be changed due to the existing of pores (Carson et al., 2005). During micro EDM, micro pores in material are helpful to store debris and bubbles, avoiding the occurrence of abnormal discharges such as arcing and short circuit. However, the influence of porous metals on the 
machining performance of micro EDM is unclear. This paper attempts to reveal the relationship between pore size and machining performance of micro EDM through extensive experiments.

\section{Experimental investigation}

\subsection{Experimental set-up and conditions}

The experiments are conducted on a four-axis horizontal type micro EDM machine tool as shown in Fig.1. The machine is equipped with XYZ linear positioning stages with travel range of $200 \mathrm{~mm}$ with resolution of $0.1 \mu \mathrm{m}$, spindle, wire electrical discharge grinding (WEDG) unit, RC circuit as the pulse generator and deionized water equipment (Yu et al., 2007). The experiments are divided into 4 groups under different machining conditions as listed in Table 1 . The pore sizes of the workpiece are listed in Table 2 .

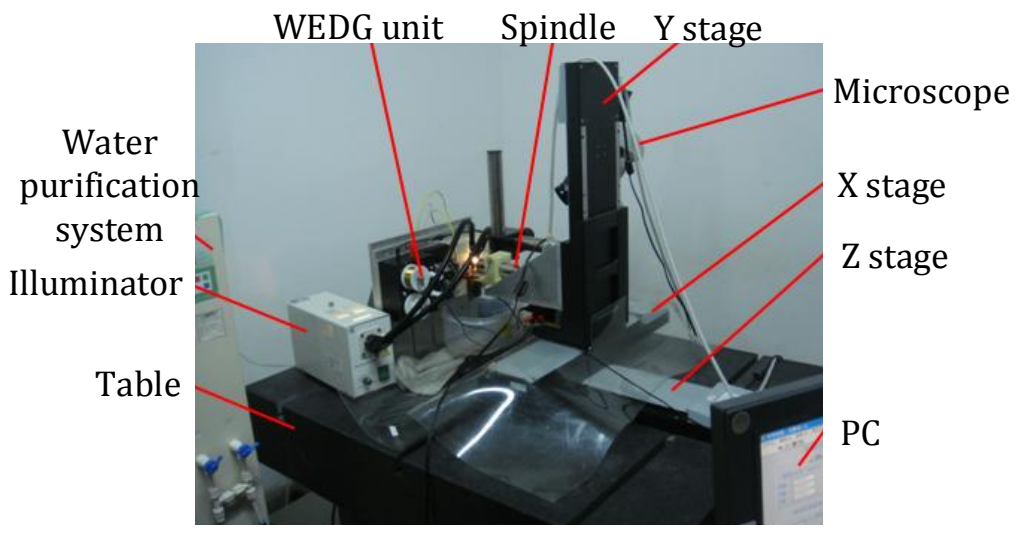

Fig. 1. Micro EDM machined tool.

Table1

Machining conditions

$\begin{array}{llll}1^{\text {st }} \text { group } & 2^{\text {nd }} \text { group } & 3^{\text {rd }} \text { group } & 4^{\text {th }} \text { group }\end{array}$

Open voltage(V) 80

Capacitance (pF) 470 100

$100, \quad 470, \quad 100, \quad 470$ $680,1000 \quad 680,1000$

Pore size of workpiece None, 1, 5, None, 1, 2, 5 10

material $(\mu \mathrm{m})$

$10,15,20$

$5,10,15$

Electrode material tungsten 
Table 2

Pore size of porous stainless steel 304

\begin{tabular}{|c|c|}
\hline 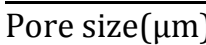 & Porosity (\% \\
\hline 1 & 28.9 \\
\hline 2 & 29.6 \\
\hline 5 & 29.0 \\
\hline 10 & 29.5 \\
\hline 15 & 30.9 \\
\hline 20 & 30.6 \\
\hline
\end{tabular}

\subsection{Experimental procedure}

In this study, the experiments are designed to drill micro holes with the depth of $600 \mu \mathrm{m}$. After an electrode is dressed to the desired diameter and length, it is fed into the workpiece. Before and after micro holes drilling, the electrode is controlled to contact a reference point on the machine. The difference on the Z-axis is the tool wear length. The diameters of electrode and drilled hole are measured using an optical microscope. The machining time is recorded. Under each machining condition, five micro holes were drilled. Material removal rate $(M R R)$, tool wear ratio $(T W R)$, and discharge gap $\left(D_{g}\right)$ are used to evaluate the machining performance of micro EDM, which are calculated using the following equations:

$$
\begin{gathered}
M R R=\frac{\pi D^{2} h(1-p)}{4 t} \\
T W R=\frac{\pi d^{2} l}{\pi D^{2} L(1-p)} \\
D_{g}=\frac{D-d}{2}
\end{gathered}
$$

where, $D$ is the diameter of micro hole, $L$ is the depth of micro hole, $t$ is the machining time, $d$ is the diameter of electrode, $l$ is the electrode wear length and $\mathrm{p}$ is the porosity of workpiece material.

\subsection{Experimental results and discussion}




\subsection{1. $1^{\text {st }}$ group and $2^{\text {nd }}$ group}

In $1^{\text {st }}$ group, experiments are carried out to investigate the relationship of machining performance and pore size under the same discharge energy of $80 \mathrm{~V}$ and capacitor at $470 \mathrm{pF}$. The results are listed in Table 3 and shown in Fig. 2, respectively. It can be seen that MRRs of porous metals are higher than that of solid metal, and the corresponding TWRs are less that of solid material. Discharge gap is about $10 \mu \mathrm{m}$ regardless of pore existing. It is noticed that the $M R R$ of pore size of $10 \mu \mathrm{m}$ is significantly less than the MRRs of other pore sizes, which is close to the discharge gap value.

Table 3

$1^{\text {st }}$ group experimental results.

\begin{tabular}{llll}
\hline Pore size $(\mu \mathrm{m})$ & MRR $\left(\mu \mathrm{m}^{3} / \mathrm{s}\right)$ & TWR $(\%)$ & $\mathrm{D}_{\mathrm{g}}(\mu \mathrm{m})$ \\
\hline None (Solid) & 11404.34 & 2.03 & 10.52 \\
1 & 13462.61 & 0.59 & 10.55 \\
5 & 14138.38 & 0.49 & 10.64 \\
10 & 12222.98 & 0.55 & 10.09 \\
15 & 13369.98 & 0.39 & 10.72 \\
20 & 13864.97 & 0.59 & 10.00 \\
\hline
\end{tabular}

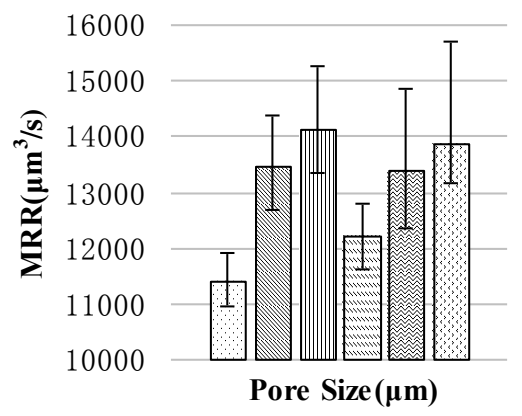

$\square$ Solid $\square 1$ 四 5 四 10 圆20

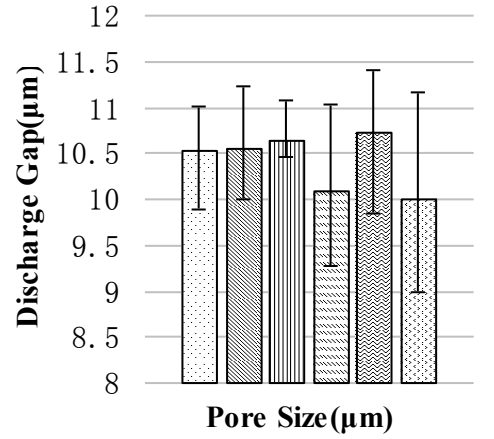

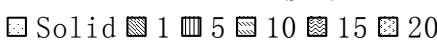

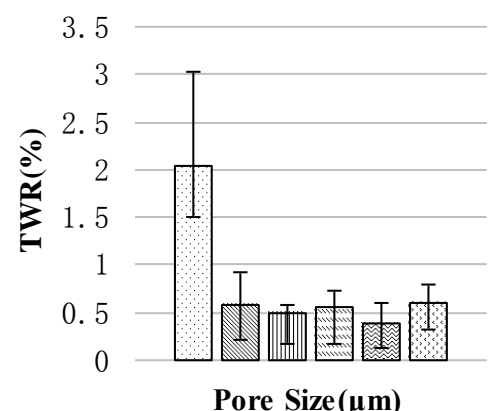

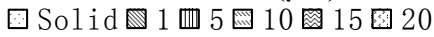
(a) $M R R$
(b) $D_{g}$
(c) TWR

Fig. 2. $1^{\text {st }}$ group experimental results. 
In $2^{\text {nd }}$ group, voltage is set at $80 \mathrm{~V}$ and capacitor at $100 \mathrm{pF}$. Experimental results listed in Table 4 and shown in Fig. 3, respectively, indicate the relationship of machining performance and pore size is similar to that of $1^{\text {st }}$ group. Minimum $M R R$ is obtained at pore size of $5 \mu \mathrm{m}$, close to the discharge gap of $6 \mu \mathrm{m}$.

Table 4

$2^{\text {nd }}$ group experimental results.

\begin{tabular}{|c|c|c|c|}
\hline Pore size $(\mu \mathrm{m}$ & $M R R\left(\mu \mathrm{m}^{3} / \mathrm{s}\right)$ & $T W R(\%)$ & $D_{g}(\mu \mathrm{m})$ \\
\hline None (Solid) & 12606.46 & 0.48 & 6.09 \\
\hline 1 & 14226.98 & 0.23 & 6.04 \\
\hline 2 & 16497.29 & 0.16 & 5.49 \\
\hline 5 & 13238.17 & 0.35 & 6.25 \\
\hline 10 & 14992.16 & 0.17 & 6.05 \\
\hline 15 & 15744.30 & 0.22 & 6.42 \\
\hline
\end{tabular}

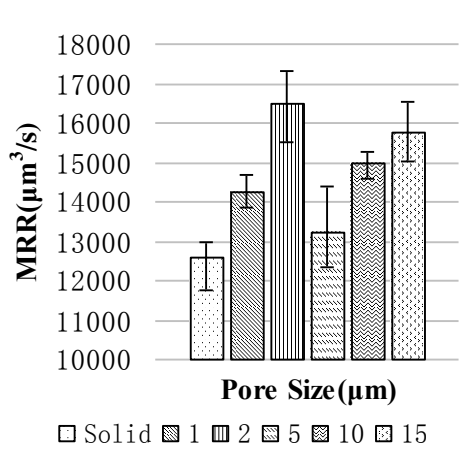

(a) $M R R$

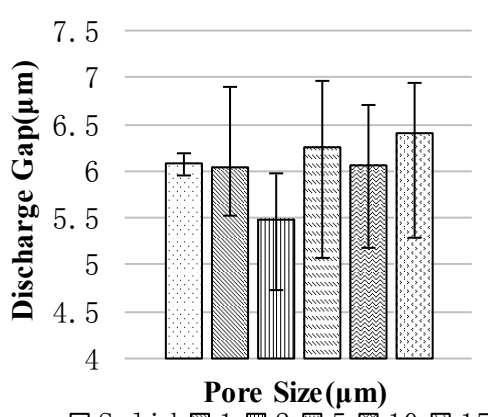

$\square$ Solid $\mathbb{8} 1$ 四 2 圆 5 图 10 圆 15

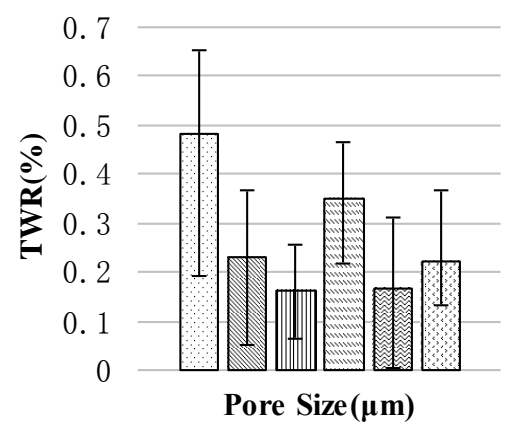

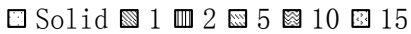

(b) $D_{g}$

(c) $T W R$

Fig. 3. $2^{\text {nd }}$ group experimental results.

\subsection{2. $3^{\text {rd }}$ group 3 and $4^{\text {th }}$ group}

To understand the relationship of machining performance and discharge energy, the workpiece material with pore size of $5 \mu \mathrm{m}$ is used in the $3^{\text {rd }}$ group experiment. Capacitor varies from $100 \mathrm{pF}$ to $1000 \mathrm{pF}$. The open circuit voltage in RC pulse generator is set at 80V. Experimental results are listed in Table 5 and shown in Fig. 4, respectively. MRRs and TWRs increase with an increase of discharge energy. When the workpiece material with pore size of $10 \mu \mathrm{m}$ is used in $4^{\text {th }}$ group, the MRRs under capacitors of $470 \mathrm{pF}$ and 
$680 \mathrm{pF}$ are lower than the other capacitors, even lower than the $M R R$ under capacitor of $100 \mathrm{pF}$. The corresponding discharge gaps are around $10 \mu \mathrm{m}$, which is close to the pore size. This further confirms that the phenomenon shown in Figs. 3 and 4, that the MRR decreases significantly when the discharge gap is close to the pore size. The mechanism of this phenomenon is analyzed in the following sections. When the discharge gap is larger than $10 \mu \mathrm{m}$, large discharge energy is needed, which may cause low surface quality and generate burrs on the edge of micro hole.

Table 5

$3^{\text {rd }}$ group experimental results.

\begin{tabular}{llll}
\hline Capacitance $(\mathrm{pF})$ & $M R R\left(\mu \mathrm{m}^{3} / \mathrm{s}\right)$ & $T W R(\%)$ & $D_{g}(\mu \mathrm{m})$ \\
\hline 100 & 13238.17 & 0.35 & 6.25 \\
470 & 14138.38 & 0.49 & 10.65 \\
680 & 20972.00 & 3.05 & 10.57 \\
1000 & 25029.76 & 3.41 & 10.66 \\
\hline
\end{tabular}

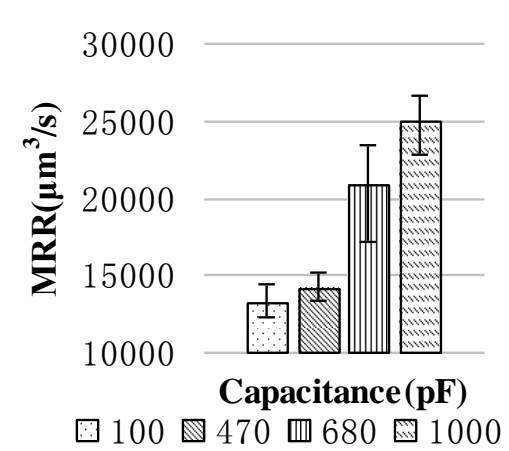

(a) $M R R$

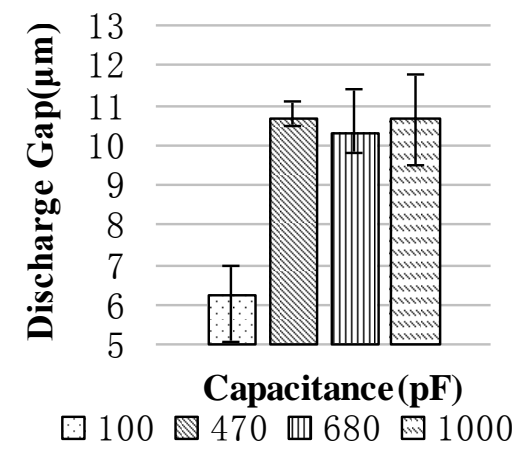

(b) $D_{g}$

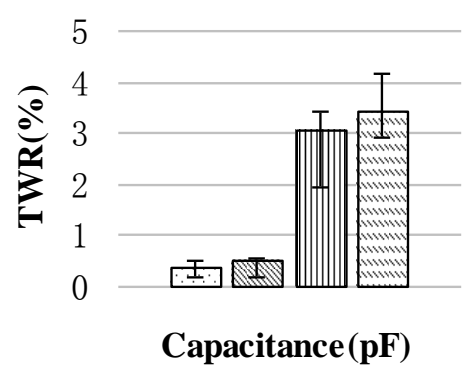

$\square 100 \quad \mathbb{8} 470 \quad$ 四680 $⿴ 1000$

Fig. 4. $3^{\text {rd }}$ group experimental results.

Table 6

$4^{\text {th }}$ group experimental results.

\begin{tabular}{llll}
\hline Capacitance $(\mathrm{pF})$ & $\mathrm{MRR}\left(\mu \mathrm{m}^{3} / \mathrm{s}\right)$ & TWR $(\%)$ & $\mathrm{D}_{\mathrm{g}}(\mu \mathrm{m})$ \\
\hline 100 & 14987.73 & 0.17 & 6.05 \\
470 & 12222.98 & 0.55 & 10.09 \\
680 & 13992.40 & 3.27 & 10.22
\end{tabular}




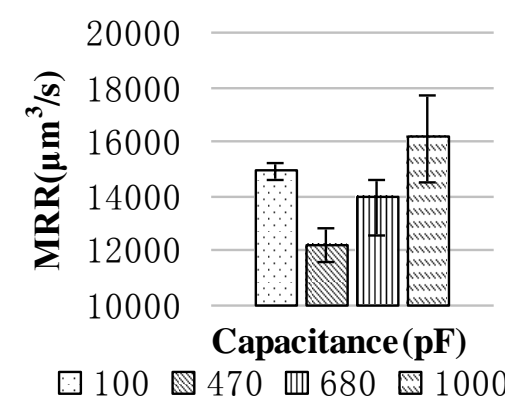

(a) $M R R$

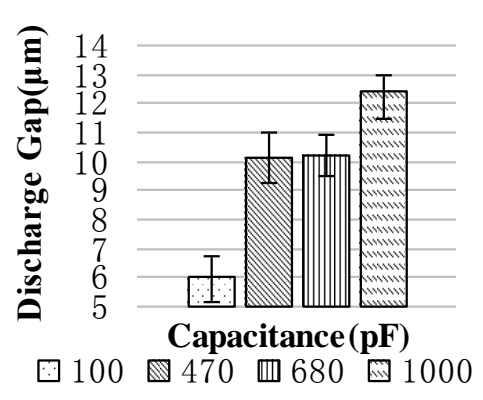

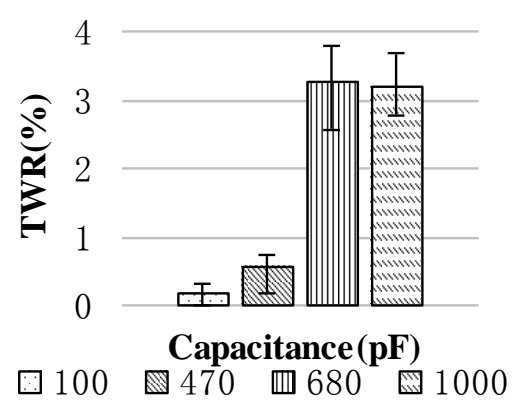

\section{Mechanism analysis of relationship between the discharge gap and pore size}

It is expected that micro hole drilling by micro EDM process is stable and smooth. The debris concentration in the narrow discharge gap may cause the occurrence of abnormal discharges such as arcing and short-circuiting. Fig. 6 shows the micro hole drilling in solid and porous materials by micro EDM. The pores unevenly distributed in porous material can be used to store debris and bubbles, avoiding the occurrence of abnormal discharges, leading to higher machining efficiency than that of solid material.

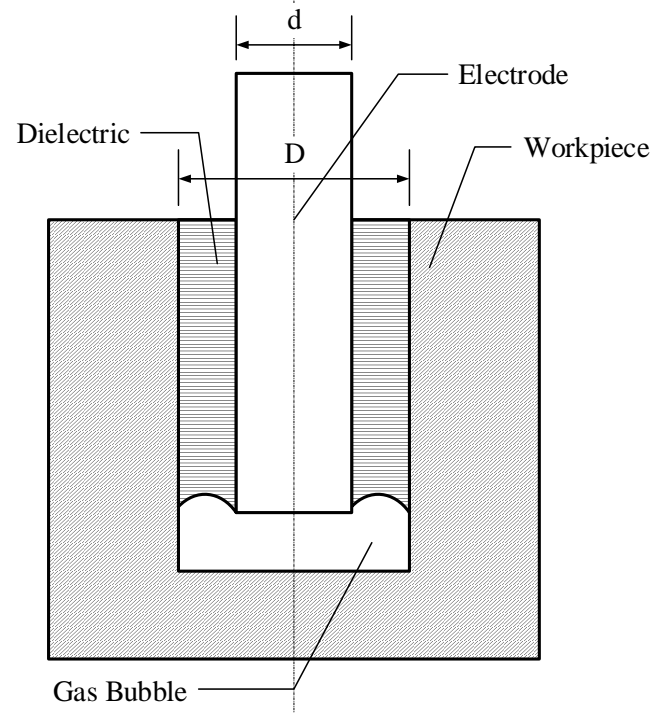

(a)Solid material.

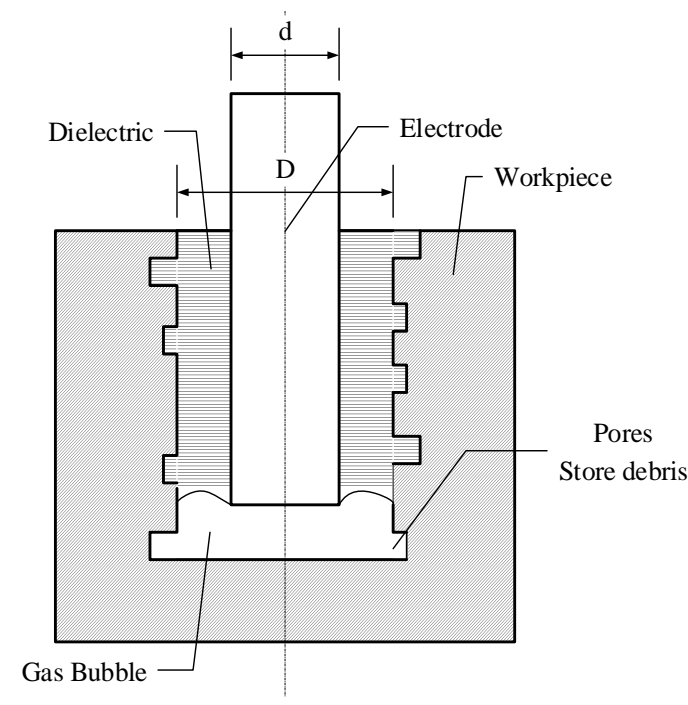

(b) Porous material.

Fig. 6. Micro hole drilling in solid and porous materials by micro EDM. 


\subsection{Assumptions in mechanism analysis}

In micro hole drilling, the $M R R$ is affected by two factors, machining ability and debris removal ability. The machining ability is dominated by discharge energy. In this study, electrode feed rate and retreat rate are set as constants. In the case of porous material, the machining ability is also influenced by the porosity and pore size of the material. $M R R$ is calculated using the following equation:

$$
M R R=f V_{0}
$$

where, $M R R$ is material remove rate, $f$ is the discharge frequency, $V_{0}$ is the volume of removed unit by a single spark.

In order to investigate the influence of machining ability and debris removal ability, the Eq. (4) is modified using the following equation:

$$
M R R=X_{M} X_{O} f V_{0}
$$

where, $X_{M}$ is the impact factor of machining ability, $X_{O}$ is the impact factor of debris removal ability.

To investigate the relationship between discharge gap and pore size, the following assumptions are made:

(1) The values of discharge gap in the electrode sidewall and bottom are equal;

(2) The volume of removed unit by a single spark under the same discharge energy is constant.

(3) The electrode feed rate is unchanged when the porosity is larger than the average porosity of material. When the porosity is less than the average porosity of material, the electrode feed rate is reduced.

In micro hole drilling by micro EDM, it is assumed that the material is removed section by section. The hole with a depth of $L$ is divided into sections by the discharge gap value. The thickness of a section is defined as $H$, which is equal to discharge gap $\left(D_{g}\right)$. Each section is further divided into several layers by the size of the pore. The thickness of a layer is defined as $h$, which is equal to the pore size, as shown in Fig. 7. 


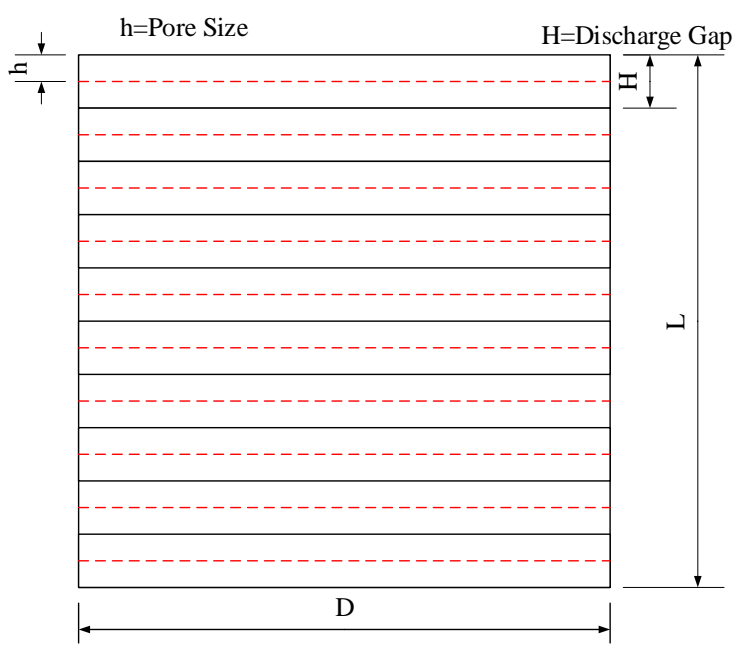

Fig. 7. Diagram of sections and layers

The porosity is unevenly distributed in each section $(H)$. Based on the assumptions, the average porosity of each section $(p)$ is calculated as

$$
p=\sum_{i}^{m} h_{i} p_{i} / H
$$

where, $m$ is the number of layers in each section, $h_{i}$ is the layer thickness, $p_{i}$ is the porosity of each layer, $H$ is the thickness of the section.

\subsection{Calculation of MRR}

To calculate the MRR of porous material by micro EDM, it is necessary to consider the influence of machining ability and debris removal ability. In this paper, $X_{M}$ and $X o$ are used to represent the influence of machining ability and debris removal ability, respectively.

When the discharge energy and the electrode feed rate are constant, there is a maximum machining ability in micro hole drilling. When reached, the volume of removed material is maximal, defined as $V_{\max }$. The highest impact factor of machining ability is defined as $X_{M \max }$. The machining ability is related closely to the porosity of material, because it influences the volume of removed material. When the $X_{\text {Mmax }}$ is reached, the porosity is defined as $p_{0}$.

When the porosity of material $p<p_{0}$, it may cause short-circuit and other abnormal discharge. In this case, the increase of machining time includes the following aspects: (1) the additional time to extricate short-circuit status during machining; (2) the additional time is consumed by the increase of material 
volume. It is too difficult to calculate the additional time used by the first aspect. Thus, in this paper, only additional time used by the second aspect is taken into account. Therefore, the following equation is used to express the machining time related to $p$,

$$
t=\frac{1-p}{1-p_{0}} \cdot t_{0}
$$

where, $t$ is the machining time of the material with the porosity of $p, t_{0}$ is the time of machining material with the porosity of $p_{0}$.

The machining ability, $X_{M}$, with a material porosity of $p$ smaller than $p_{0}$, can be calculated by the following equation,

$$
X_{M}(p)=X_{M \max } \cdot \frac{1-p_{0}}{1-p}
$$

where, $X_{M}(p)$ is the impact factor of machining ability for porous material with the porosity of $p, X_{M \max }$ (its value $=100 \%$ ) is the highest impact factor of machining ability. The corresponding material porosity is $p_{0}$.

When $p>p_{0}$, the insufficient of material removal volume results in the decrease of MRR. In this case, $X_{M}(p)$ can be calculated by the following equation:

$$
X_{M}(p)=X_{M \max } \cdot \frac{1-p}{1-p_{0}}
$$

Thus, Eq. (8) and Eq. (9) can be summarized into Eq. (10).

$$
X_{M}(p)=\left\{\begin{array}{l}
X_{M \max } \cdot \frac{1-p_{0}}{1-p}, p \leq p_{0} \\
X_{M \max } \cdot \frac{1-p}{1-p_{0}}, p>p_{0}
\end{array}\right.
$$

where, $X_{M}(p)$ is the impact factor of machining ability for porous material with the porosity of $p, X_{M \max }$ is the highest impact factor of machining ability , $p_{0}$ is the corresponding material porosity.

Based on Eq. (6) and (10), the average section machining ability related to the pore size, $i, X_{M i}$, is calculated as

$$
X_{M i}=\frac{1}{n} \sum_{j=1}^{n} X_{M}{ }^{j}(p)
$$

where, $X_{M i}$ is the impact factor of machining ability for porous material with pore size of $i \mu \mathrm{m} . X_{M}{ }^{j}(p)$ is the impact factor of machining ability for section $j . n$ is the section number in a hole. 
Fig. 8 shows the cross section of a drilled hole. It can be seen that there are valid pores available to temporarily store the removed debris to avoid abnormal discharges and invalid pores which disconnect to the drilled hole.

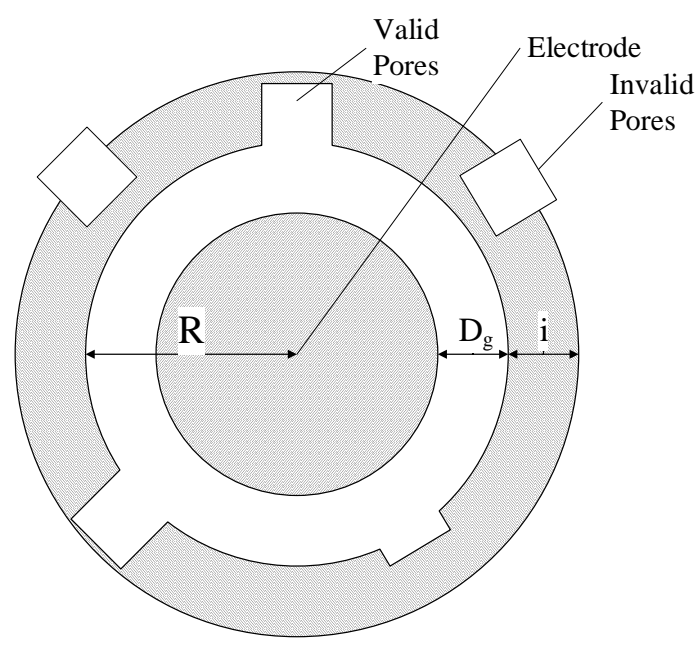

Fig. 8. Cross-section of micro hole drilling in porous materials by micro EDM.

The area used to store the debris in Fig. 8 can be calculated by Eq. (12)

$$
S=\pi R^{2}+\pi\left[(R+i)^{2}-R^{2}\right] p k
$$

where, $i$ is pore size, $R$ is the radius of micro hole, $p$ is the porosity of material, $k$ is the ratio of valid pores. $R$ can be calculated by Eq. (13)

$$
R=\frac{d}{2}+D_{g}
$$

where, $R$ is the radius of micro hole, $d$ is the electrode diameter, $D_{g}$ is the discharge gap.

The debris removal ability, $X_{0}(I, p)$, is related to the area used to store the debris, which is expressed by Eq. (14)

$$
\begin{aligned}
& X_{o}(i, p)=\frac{S(i, p)}{S_{\max }(i, p)}=\frac{\pi R^{2}+\pi\left[(R+i)^{2}-R^{2}\right] p k}{\pi R^{2}+\pi\left[\left(R+i_{\max }\right)^{2}-R^{2}\right] p_{\max } k} \\
& =\frac{(1-p k) R^{2}+p k(R+i)^{2}}{\left(1-p_{\max } k\right) R^{2}+p_{\max } k\left(R+i_{\max }\right)^{2}}
\end{aligned}
$$

where, $i$ is pore size, $i_{\max }$ is the maximum of pore size, $R$ is the radius of micro hole, $p$ is the material porosity, $p_{\max }$ is the maximum of material porosity, $k$ is the ratio of valid pores. 
The ratio of valid pores, $k$, is defined as the ratio of number of valid pores and number of all pores in the annulus area, which is composed by a circle with the radius of $R$ and another circle with the radius of $R+\mathrm{i}$, as shown in Fig. 8. It is impossible to calculate the actual $k$. For a pore, it is either a valid hole or an invalid hole. Thus, $k$ is valued as 0.5 in this paper.

$X_{O i}$ is the impact factor of debris removal ability for porous material with pore size of $i \mu \mathrm{m}$. It is the average of the $X_{O}$ of all sections in a hole. It can be calculated by Eq.(15)

$$
X_{O i}=\frac{1}{n} \sum_{j=1}^{n} X_{O}^{j}(i, p)
$$

where, $X_{O i}$ is the impact factor of debris removal ability for porous material with pore size of $i \mu \mathrm{m}$, $X_{o}^{j}(i, p)$ is the impact factor of debris removal ability of section $j$ and the pore size is $i \mu \mathrm{m} . n$ is the section number in a hole.

Under the same discharge conditions, the discharge frequency, $f$, and the removal volume of one discharge pulse, $V_{0}$, can be assumed as a constant. In Figs. 2 and 3, it can be found that the debris removal ability increases as the increases of pore size, which indicates that $X_{O i}$ increases with an increase of the pore size. The lowest $M R R$ can be found when the pore size was close to the discharge gap among porous materials. The $X_{M}(p)$ has a negative effect in that the $M R R$ increases when the pore size is close to or far away from the value of discharge gap.

\section{Analysis of experimental results}

\subsection{Porosity and its distribution}

The mean porosity of material used in this paper is $30 \%$. The distribution of pores is very complicated and impossible to be uniform. A simplified distribution is assumed in order to explain the experimental results in this paper. The distribution order of porosity is listed in Table 7.

Table 7

Porosity, distribution and its order 


\begin{tabular}{ccc}
\hline Porosity (\%) & Distribution & Distribution order \\
\hline 10 & $1 / 6$ & Layer 1 \\
50 & $1 / 6$ & Layer 2 \\
30 & $4 / 6$ & Layer 3, 4, 5 \& 6 \\
\hline
\end{tabular}

\subsection{Theoretical calculation of $1^{\text {st }}$ group experiments}

In $1^{\text {st }}$ group experiments, the discharge gap, $D_{g}$, is about $10 \mu \mathrm{m}$. In other words, the thickness of each section $(H)$ is $10 \mu \mathrm{m}$. The hole depth $(L)$ is simplified as $100 \mu \mathrm{m}$. There are 10 sections in the length of $L$. $X_{M}(10 \%), X_{M}(30 \%)$ and $X_{M}(50 \%)$ are used to describe the machining ability related to porosity. As listed in Table 1, pore size varies from $1 \mu \mathrm{m}$ to $20 \mu \mathrm{m}$. The variables, $X_{M 1}$ to $X_{M 20}$, are used to describe the average machining ability of each section related to the pore size. That means the maximum of material porosity $\left(p_{\max }\right)$ is $50 \%$ and the maximum of pore size $\left(i_{\max }\right)$ is $20 \mu \mathrm{m}$. As listed in Table 1 , the diameter of electrode is $80 \pm 5 \mu \mathrm{m}$ in this study. Based on Eq. (13), the hole radius, $R$, is $50 \mu \mathrm{m}$. The area used to store the debris is calculated using Eq. (12)

$$
S_{\text {max }}=\pi R^{2}+\pi\left[\left(R+i_{\text {max }}\right)^{2}-R^{2}\right] p_{\text {max }} k=3100 \pi
$$

In the case of pore size of $1 \mu \mathrm{m}$, each section has 10 layers. Bases on the assumptions listed in Table 7 , the distribution of first three sections are shown in Fig. 9. It is easy to obtain that the average porosity is $30 \%$. It is also found that the distribution of the fourth section is the same as the first section. Therefore, the average porosity of each section of material with pore size $1 \mu \mathrm{m}$ is $30 \%$.

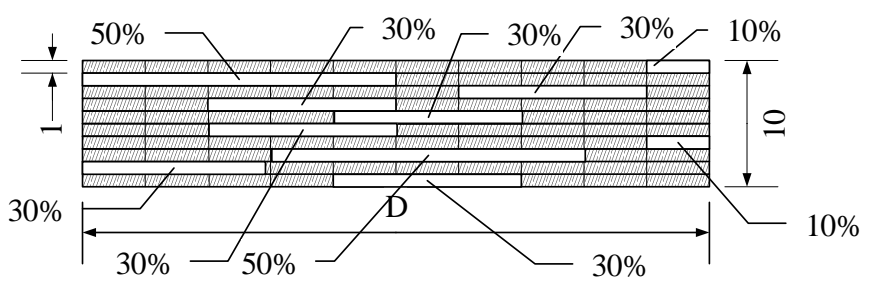

(a) distribution of the first section. 


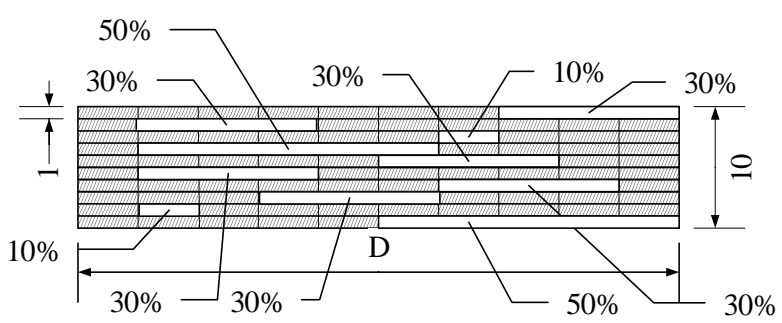

(b) distribution of the second section.

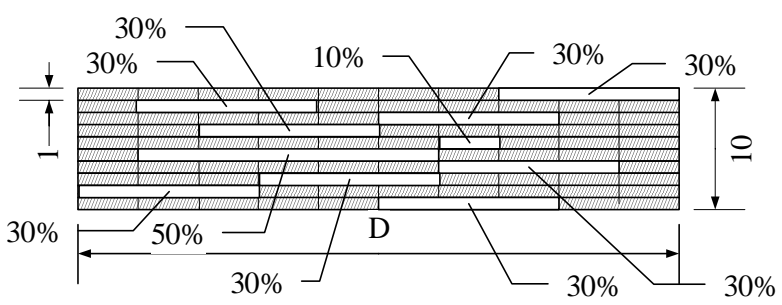

(c) distribution of the third section.

Fig. 9 Porosity and distribution of material with pore size $1 \mu \mathrm{m}$.

Based on Fig. 9 and Eqs. (10), (14) and (15), the following Equations can be obtained:

$$
\begin{gathered}
X_{M 1}=X_{M}(30 \%) \\
X_{O 1}=\frac{1}{10} \sum_{j=1}^{10} X_{O}^{j}(1,30 \%)=X_{O}(1,30 \%)=\frac{2515.15}{3100}=81.13 \%
\end{gathered}
$$

When the pore size is $5 \mu \mathrm{m}$, its distribution is shown in Fig. 10. The average porosity of each section of material with pore size $5 \mu \mathrm{m}$ is also $30 \%$.

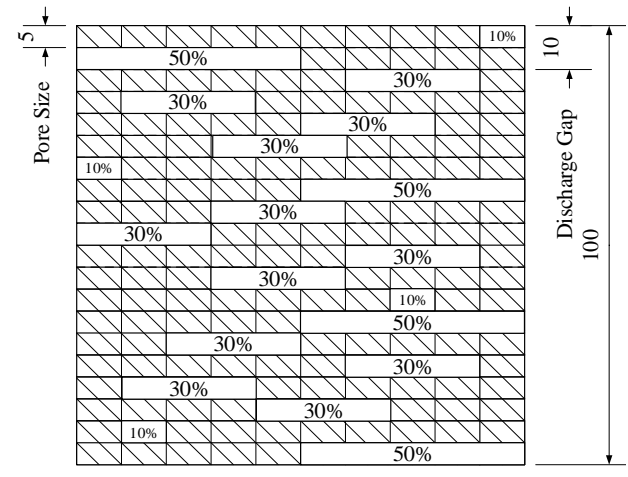

Fig. 10 Porosity and distribution of material with pore size $5 \mu \mathrm{m}$.

The following equations can be obtained: 


$$
\begin{gathered}
X_{M 5}=X_{M}(30 \%) \\
X_{O 5}=X_{O}(5,30 \%)=83.19 \%
\end{gathered}
$$

The porosity and its distribution of pore size $10 \mu \mathrm{m}$ are shown in Fig. $11 . X_{M 10}$ and $X_{O 10}$ are calculated using Eq. (11) and Eq. (15) as

$$
\begin{gathered}
X_{M 10}=\frac{1}{10}\left[2 \times X_{M}(10 \%)+2 \times X_{M}(50 \%)+6 \times X_{M}(30 \%)\right] \\
X_{O 10}=\frac{1}{10}\left[2 \times X_{O}(10,10 \%)+2 \times X_{o}(10,50 \%)+6 \times X_{O}(10,30 \%)\right]=85.97 \%
\end{gathered}
$$

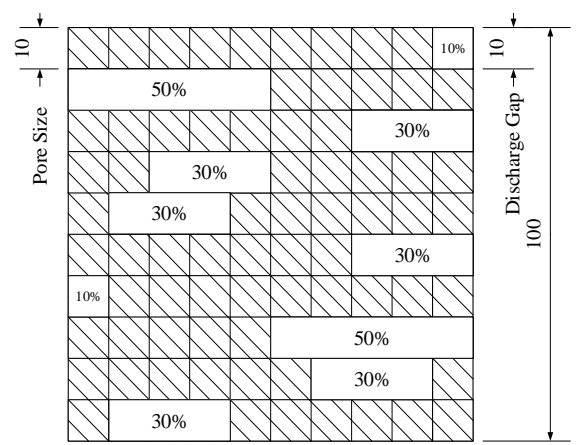

Fig. 11 Porosity and distribution of pore size $10 \mu \mathrm{m}$.

Fig. 12 shows the porosity and its distribution of pore size $15 \mu \mathrm{m}$. The $X_{M 15}$ and $X_{O 10}$ are calculated as

$$
\begin{gathered}
X_{M 15}=\frac{1}{10}\left[2 \times X_{M}(10 \%)+1 \times X_{M}(50 \%)+7 \times X_{M}(30 \%)\right] \\
X_{O 15}=\frac{1}{10}\left[2 \times X_{O}(15,10 \%)+1 \times X_{O}(15,50 \%)+7 \times X_{o}(15,30 \%)\right]=88.43 \%
\end{gathered}
$$




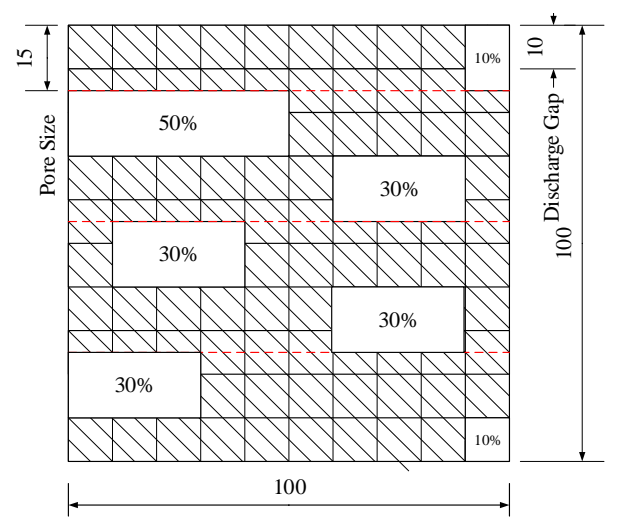

Fig. 12 Porosity and distribution of pore size $15 \mu \mathrm{m}$.

The case of $20 \mu \mathrm{m}$ is shown in Fig. 13. The $X_{M 20}$ and $X_{O 20}$ are expressed as

$$
\begin{gathered}
X_{M 20}=\frac{1}{10}\left[2 \times X_{M}(10 \%)+2 \times X_{M}(50 \%)+6 \times X_{M}(30 \%)\right] \\
X_{O 20}=\frac{1}{10}\left[2 \times X_{O}(20,10 \%)+2 \times X_{o}(20,50 \%)+6 \times X_{o}(20,30 \%)\right]=92.26 \%
\end{gathered}
$$

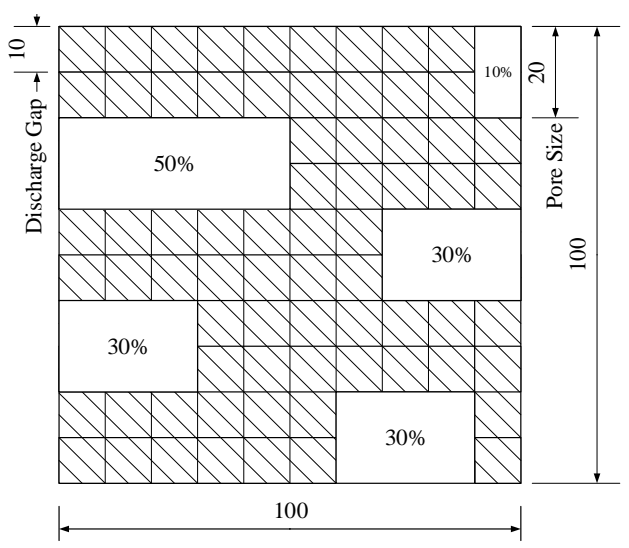

Fig. 13 Porosity and distribution of pore size $20 \mu \mathrm{m}$.

Based on the analysis above, it can be summarized: $X_{M 1}=X_{M 5}=X_{M}(30 \%)$ and $X_{O 20}>X_{015}>X_{010}>X_{O 1}>X_{O S}$. It is known that $M R R_{5}$ is the highest in $1^{\text {st }}$ group from the experimental results of Fig. 2. Therefore, The $X_{M 1}$ and $X_{M 5}$ are higher than the other porous size materials.

Taking $i=0, p=0$ into Eq. (14), $X_{O S}=80.65 \%$ can be obtained. Based on Eq. (17), $X_{O S} / X_{O 1}=0.9941$. However, $M R R_{S} / M R R_{1}=0.8471$. Therefore, it can be assumed that $30 \%$ is the optimal porosity for the material machining ability in Eq. (10). In other words, $p_{0}$ is assumed to be $30 \%$. Taking $p_{0}=30 \%$ into Eq. (10): 


$$
\begin{aligned}
& X_{M}(0)=\frac{1-30 \%}{1}=70 \%, X_{M}(10 \%)=\frac{1-30 \%}{1-10 \%}=77.78 \%, X_{M}(30 \%)=100 \%, \\
& X_{M}(50 \%)=\frac{1-50 \%}{1-30 \%}=71.43 \% .
\end{aligned}
$$

Thus, the following results can be summarized:

$$
X_{M S}=70 \%, X_{M 1}=X_{M 5}=100 \%, X_{M 10}=89.84 \%, X_{M 15}=92.70 \%, X_{M 20}=89.84 \% \text {. }
$$

Based on Eq. (5) and assumptions of this paper, the $M R R$ can be evaluated by the product of $X_{M}$ and $X_{O}$ under the same machining conditions. The relationship of $X_{M} \cdot X_{O}, X_{M}$ and $X_{O}$ is shown in Fig. 14.

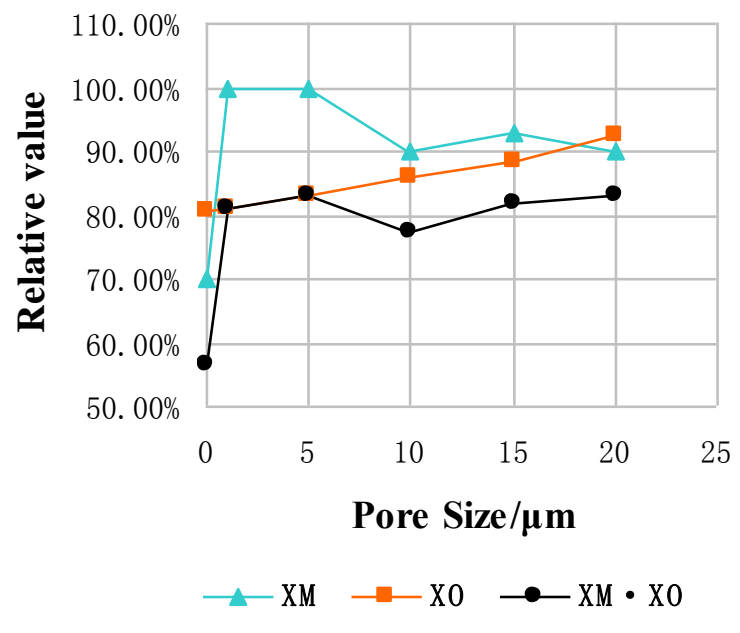

Fig. 14 Relationship of $X_{M} \cdot X_{O}, X_{M}$ and $X_{O}$ of $1^{\text {st }}$ group.

It can be seen that the debris removal ability, $X_{0}$, increases with the increase of pore size. The machining ability, $X_{M}$, varies with pore size.

To further analyze the experimental results, theoretical relative $M R R$ ratios and experimental relative $M R R$ ratios are compared and listed in Table 8. The theoretical relative MRR ratio is calculated by each $X_{M i} \cdot X_{0 i}$ dividing $X_{M 5} \cdot X_{05}$, the maximum $M R R$. The experimental relative $M R R$ ratio is obtained by $M R R_{i}$ dividing $M R R_{5}$. Fig. 15 also shows this comparison. The well-matched results indicate that the MRR of porous material is significantly influenced by the pore size.

However, there are still some difference between the experimental results and theoretical results. The possible reason is that the theoretical model in this paper is too simple to completely reflect the complicated actual distribution of porosity. 
In fact, pores are unevenly distributed in porous material. When the pore size is small, such as 1 or $2 \mu \mathrm{m}$, and the discharge gap is much larger than the pore size, the average porosity in one discharge gap is close to the average porosity of material. This shows that $M R R$ increases with an increase of pore size. When the discharge gap is close to the pore size and the porosity in one discharge gap is less than the average porosity, the $M R R$ decreases significantly, leading to minimum $M R R$. When the pore size is larger than the discharge gap, the debris removal ability increases while the porosity in one discharge gap may be less than the average porosity, resulting in the low $M R R$.

Table 8

Comparison of theoretical relative $M R R$ ratio and experimental relative $M R R$ ratio of $1^{\text {st }}$ group.

\begin{tabular}{cccc}
\hline Pore size $(\mu \mathrm{m})$ & $\mathrm{X}_{\mathrm{M}} \cdot \mathrm{X}_{0}(\%)$ & Theoretical relative $M R R$ ratio (\%) & Experimental relative $M R R$ ratio (\%) \\
\hline 0 & 56.46 & 67.86 & 80.66 \\
1 & 81.13 & 97.52 & 95.22 \\
5 & 83.19 & 100.00 & 100.00 \\
10 & 77.24 & 92.84 & 86.45 \\
15 & 81.97 & 98.54 & 94.57 \\
20 & 82.89 & 99.64 & 98.07 \\
\hline
\end{tabular}

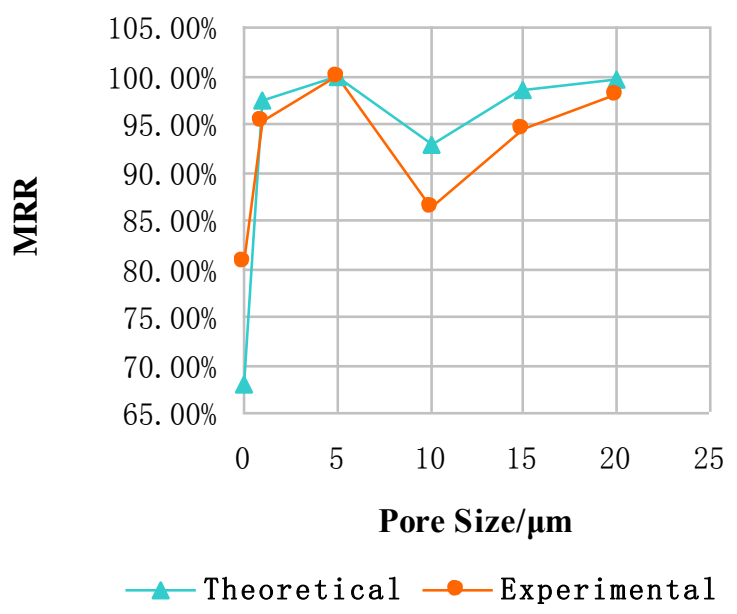

Fig. 15 Comparison of theoretical relative $M R R$ ratio and experimental relative $M R R$ ratio of $1^{\text {st }}$ group. 
In $2^{\text {nd }}$ group experiments, the discharge gap is about $6 \mu \mathrm{m}$. In other words, the thickness of each section $(H)$ is $6 \mu \mathrm{m}$. The hole depth $(L)$ is simplified as $102 \mu \mathrm{m}$ in mechanism analysis. There are 17 sections in the length of $L$. The maximum of pore size $\left(i_{\max }\right)$ in $2^{\text {nd }}$ group is $15 \mu \mathrm{m}$. The maximum of material porosity $\left(p_{\max }\right)$ is also $50 \%$. As listed in Table 1 , the diameter of electrode is $80 \pm 5 \mu \mathrm{m}$ in this study. The hole radius is $46 \mu \mathrm{m}$. The ratio of valid pores $(k)$ is also 0.5 . Take these values into Eq. (12):

$$
S_{\max }=\pi R^{2}+\pi\left[\left(R+i_{\max }\right)^{2}-R^{2}\right] p_{\max } k=2517.25 \pi
$$

The calculating process and method of $2^{\text {nd }}$ group experiments is the same as the $1^{\text {st }}$ group. The theoretical results of $2^{\text {nd }}$ group were summarized as follow:

$$
\begin{aligned}
X_{O S} & =\frac{\pi 46^{2}}{2517.25 \pi}=84.06 \% \\
X_{O 1} & =\frac{1}{17} \sum_{j=1}^{17} X_{O}^{j}(1,30 \%)=X_{O}(1,30 \%)=\frac{2129.95}{2517.25}=84.61 \% \\
X_{O 2} & =\frac{1}{17} \sum_{j=1}^{17} X_{O}^{j}(2,30 \%)=X_{O}(2,30 \%)=\frac{2144.2}{2517.25}=85.18 \% \\
X_{O 5} & =\frac{1}{17}\left[4 \times X_{O}(5,16.67 \%)+4 \times X_{O}(5,43.33 \%)+9 \times X_{o}(5,30 \%)\right]=86.80 \% \\
X_{O 10} & =\frac{1}{17}\left[\begin{array}{l}
2 \times X_{O}(10,10 \%)+2 \times X_{O}(10,23.33 \%)+2 \times X_{O}(10,36.67 \%) \\
+2 \times X_{O}(10,50 \%)+9 \times X_{O}(10,30 \%)
\end{array}\right]=90.14 \% \\
X_{O 15} & =\frac{1}{17}\left[4 \times X_{O}(15,10 \%)+2 \times X_{O}(15,50 \%)+11 \times X_{O}(15,30 \%)\right]=92.87 \% \\
X_{M S}=70 \%, X_{M 1} & =X_{M 2}=100 \%, X_{M 5}=91.75 \%, X_{M 10}=91.88 \%, X_{M 15}=91.41 \% .
\end{aligned}
$$

The relationship of $X_{M} \cdot X_{O}, X_{M}$ and $X_{O}$ is shown in Fig. 16. 


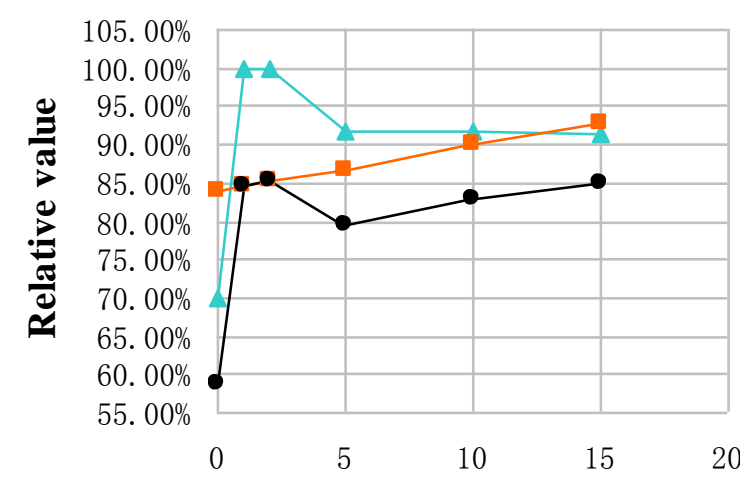

Pore Size $/ \mu \mathrm{m}$

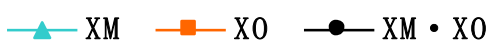

Fig. 16 Relationship of $X_{M} \cdot X_{O}, X_{M}$ and $X_{O}$ of $2^{\text {nd }}$ group.

The comparison of theoretical results and experimental results of $2^{\text {nd }}$ group are shown in Fig.17 and listed in Table 9. The results are also well matched. The difference between the experimental results and theoretical results is caused by similar reasons as the analysis of $1^{\text {st }}$ group results.

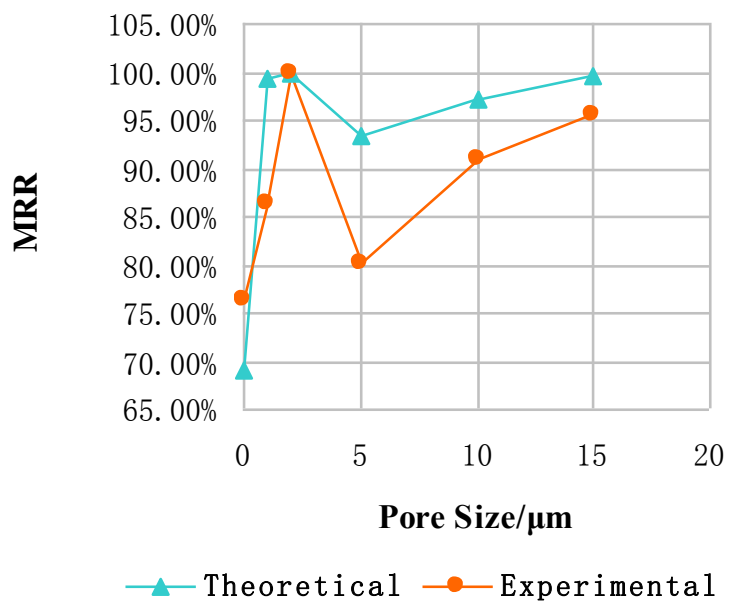

Fig. 17 Comparison of theoretical relative $M R R$ ratio and experimental relative $M R R$ ratio of $2^{\text {nd }}$ group.

Table 9

Comparison of theoretical relative $M R R$ ratio and experimental relative $M R R$ ratio of $2^{\text {nd }}$ group.

Pore size $(\mu \mathrm{m}) \quad \mathrm{X}_{\mathrm{M}} \cdot \mathrm{X}_{0}(\%) \quad$ Theoretical relative $M R R$ ratio (\%) $\quad$ Experimental relative $M R R$ ratio (\%) 


\begin{tabular}{llll}
\hline 0 & 58.84 & 69.08 & 76.42 \\
1 & 84.61 & 99.33 & 86.24 \\
2 & 85.18 & 100.00 & 100.00 \\
5 & 79.64 & 93.49 & 80.24 \\
10 & 82.82 & 97.23 & 90.88 \\
15 & 84.89 & 99.66 & 95.44 \\
\hline
\end{tabular}

\section{Conclusions}

The microstructure of material influences the machining performance of micro EDM. In this paper, experiments were conducted on solid and porous stainless steel 304, respectively. It was found that the $M R R$ of porous material is larger than that of solid material. It was also found that the pore size influences on the MRR significantly. When the pore size is smaller than the discharge gap, such as pore size of 1 or $5 \mu \mathrm{m}$, the average porosity in the discharge gap is same as that of porous material. The $M R R$ increases with an increase of pore size. When the discharge gap is close to the pore size, the minimum $M R R$ was obtained because the porosity in some discharge gaps is less than the average porosity, resulting in the low machining ability. When the pore size is larger than the discharge gap, the porosity in some discharge gaps is less than the average one, leading to low machining ability, while the debris removal ability increases. To evaluate the influence of pore size on the $M R R$, the machining ability and the debris removal ability were proposed. The theoretical relative $M R R$ ratio matches the experimental results very well.

\section{Acknowledgements}

Authors are thankful for the support from the National Science Foundation of China (NSFC) (No. 51475057 and 51175062) and National Research Foundation for the Doctoral Program of Higher Education of China (No. 20120041110033).

\section{References}

Azzi, W., Roberts, W.L., Rabiei, A., 2007. A study on pressure drop and heat transfer in open cell metal foams for jet engine applications. Materials \& Design 28, 569-574. 
Banhart, J., 2001. Manufacture, characterisation and application of cellular metals and metal foams. Progress in Materials Science 46, 559-632.

Carson, J.K., Lovatt, S.J., Tanner, D.J., Cleland, A.C., 2005. Thermal conductivity bounds for isotropic, porous materials. International Journal of Heat and Mass Transfer 48, 2150-2158.

Chung, D., Shin, H., Park, M., Kim, B., Chu, C., 2011. Recent researches in micro electrical machining. Int. J. Precis. Eng. Manuf. 12, 371-380.

Dewidar, M.M., Khalil, K.A., Lim, J.K., 2007. Processing and mechanical properties of porous 316L stainless steel for biomedical applications. Transactions of Nonferrous Metals Society of China 17, 468-473.

Liu, P., 2004. Introduction to Porous Materials. Beijing: Tsinghua University Press.

Mohazzabi, P., Hill, W., 2013. A simple method for accurate determination of porosity using ideal gas law. J Porous Mater 20, 441-445.

Muth, J., Poggie, M., Kulesha, G., Michael Meneghini, R., 2013. Novel Highly Porous Metal Technology in Artificial Hip and Knee Replacement: Processing Methodologies and Clinical Applications. JOM 65, 318-325.

Rajurkar, K.P., Levy, G., Malshe, A., Sundaram, M.M., McGeough, J., Hu, X., Resnick, R., DeSilva, A., 2006. Micro and Nano Machining by Electro-Physical and Chemical Processes. CIRP Annals - Manufacturing Technology 55, 643-666.

Yu, Z., Guo, D., Jia, Z., 2007. Micro electrical discharge machining technology. Sciencepaper Online 2, 214220 (in Chinese). 
Fig. 2. Micro EDM machined tool.

Fig. 2. $1^{\text {st }}$ group experimental results.

Fig. 3. $2^{\text {nd }}$ group experimental results.

Fig. 4. $3^{\text {rd }}$ group experimental results.

Fig. 5. $4^{\text {th }}$ group experimental results.

Fig. 6. Micro hole drilling in solid and porous materials by micro EDM.

Fig. 7. Diagram of sections and layers

Fig. 8. Cross-section of micro hole drilling in porous materials by micro EDM.

Fig. 9 Porosity and distribution of material with pore size $1 \mu \mathrm{m}$.

Fig. 10 Porosity and distribution of material with pore size $5 \mu \mathrm{m}$.

Fig. 11 Porosity and distribution of pore size $10 \mu \mathrm{m}$.

Fig. 12 Porosity and distribution of pore size $15 \mu \mathrm{m}$.

Fig. 13 Porosity and distribution of pore size $20 \mu \mathrm{m}$.

Fig. 14 Relationship of $X_{M} \cdot X_{O}, X_{M}$ and $X_{O}$ of $1^{\text {st }}$ group.

Fig. 15 Comparison of theoretical relative $M R R$ ratio and experimental relative $M R R$ ratio of $1^{\text {st }}$ group.

Fig. 16 Relationship of $X_{M} \cdot X_{O}, X_{M}$ and $X_{O}$ of $2^{\text {nd }}$ group.

Fig. 17 Comparison of theoretical relative $M R R$ ratio and experimental relative $M R R$ ratio of $2^{\text {nd }}$ group. 